\title{
Detection of organic compound signatures in infra-red, limb emission spectra observed by the MIPAS-B2 balloon instrument
}

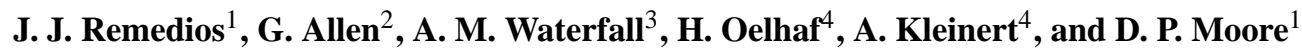 \\ ${ }^{1}$ EOS, Space Research Centre, Department of Physics and Astronomy, University of Leicester, Leicester, LE1 7RH, UK \\ ${ }^{2}$ School of Earth, Atmospheric and Environmental Sciences, The University of Manchester, Manchester, M13 9PL, UK \\ ${ }^{3}$ Atmospheric Science, Space Science and Technology Department, CCLRC Rutherford Appleton Laboratory, Chilton, \\ Didcot, Oxfordshire, OX11 0QX, UK \\ ${ }^{4}$ Institut für Meteorologie und Klimaforschung, Forschungszentrum Karlsruhe, Karlsruhe, Germany
}

Received: 25 August 2006 - Published in Atmos. Chem. Phys. Discuss.: 11 October 2006

Revised: 12 February 2007 - Accepted: 14 March 2007 - Published: 26 March 2007

\begin{abstract}
Organic compounds play a central role in troposphere chemistry and increasingly are a viable target for remote sensing observations. In this paper, infra-red spectral features of three organic compounds are investigated in thermal emission spectra recorded on a flight on 8 May 1998 near Aire sur l'Adour by a balloon-borne instrument, MIPASB2, operating at high spectral resolution. It is demonstrated, for the first time, that PAN and acetone can be detected in infra-red remote sensing spectra of the upper troposphere; detection results are presented at tangent altitudes of $10.4 \mathrm{~km}$ and $7.5 \mathrm{~km}$ (not acetone). In addition, the results provide the first observation of spectral features of formic acid in thermal emission, as opposed to solar occultation, and confirm that concentrations of this gas are measurable in the mid-latitude upper troposphere, given accurate spectroscopic data. For PAN, two bands are observed centred at $794 \mathrm{~cm}^{-1}$ and $1163 \mathrm{~cm}^{-1}$. For acetone and formic acid, one band has been detected for each so far with band centres at $1218 \mathrm{~cm}^{-1}$ and $1105 \mathrm{~cm}^{-1}$ respectively. Mixing ratios inferred at $10.4 \mathrm{~km}$ tangent altitude are $180 \mathrm{pptv}$ and $530 \mathrm{pptv}$ for PAN and acetone respectively, and $200 \mathrm{pptv}$ for formic acid with HITRAN 2000 spectroscopy. Accuracies are on the order of 15 to $40 \%$. The detection technique applied here is verified by examining weak but known signatures of CFC12 and HCFC-22 in the same spectral regions as those of the organic compounds, with results confirming the quality of both the instrument and the radiative transfer model. The results suggest the possibility of global sensing of the organic compounds studied here which would be a major step forward in verifying and interpreting global tropospheric model calculations.
\end{abstract}

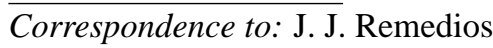

(jjr8@leicester.ac.uk)

\section{Introduction}

Volatile organic compounds (VOCs) are a well recognised and important component of the chemistry of the troposphere, influencing both ozone and hydroxyl radical concentrations and their trends (Jacob, 2000). Hence there has been great interest in observation of these compounds using both in situ, and more recently, remote sensing techniques. We concentrate here on three organic molecules: peroxyacetyl nitrate (PAN), acetone and formic acid. Acetone is believed to be important in the upper troposphere as a source of hydroxyl radicals and hence to have implications for the mediation of ozone in low water vapour $(<100 \mathrm{ppmv})$ conditions (Folkins and Chatfield, 2000). The photolysis of acetone leads to the production of PAN through reaction of the peroxyacetyl radical with $\mathrm{NO}_{2}$, thus linking VOC and nitrogen oxide $\left(\mathrm{NO}_{\mathrm{x}}\right)$ chemistry. The long lifetime of PAN at the cold temperatures of the upper troposphere (of the order of several weeks; Talukdar et al., 1995) can allow $\mathrm{NO}_{\mathrm{x}}$ to be sequestered and transported until it is released at lower and warmer altitudes, potentially resulting in ozone production in remote regions (e.g. Singh et al., 1981). Formic acid is noted to be one of the most abundant organic compounds in the troposphere but is expected to be highly variable due to its solubility (Chebbi and Carlier, 1996).

Recent aircraft campaigns to study upper tropospheric chemistry have revealed, using gas chromatography measurements, that acetone and PAN are ubiquitous in the midto upper troposphere with high concentrations reported in some regions of up to $4500 \mathrm{pptv}$ for acetone and $660 \mathrm{pptv}$ for PAN (e.g. Russo et al., 2003; Pöschl et al., 2001; Roberts et al., 2004). Observed upper tropospheric concentrations of formic acid range from as little as $10 \mathrm{pptv}$ to nearly $600 \mathrm{pptv}$ (Reiner et al., 1999). The variability of these compounds and the regional/temporal nature of enhancements in concentrations suggest strongly that more extensive and regular

Published by Copernicus GmbH on behalf of the European Geosciences Union. 
measurements of VOC concentrations would provide considerable new information. In the 1990s, only the Global Ozone Monitoring Experiment (Burrows et al., 1999) was able to provide satellite-based, global measurements of such compounds, in the form of formaldehyde columns from visible wavelength observations. Since 2000, there has been a revolution in abilities to sense organic compounds with parallel studies of glyoxal (e.g. Wittrock et al., 2006) and methanol (Dufour et al., 2006) complementing the investigations of PAN, acetone and formic acid which are reported in this paper.

With the increasing use of infra-red spectrometers, particularly in satellite systems, the detection of organic compound signatures in observed atmospheric spectra, as for methanol (Dufour et al., 2006) can significantly increase measurement capability and would allow global mapping of such compounds. In this paper, we examine the signatures of PAN, acetone and formic acid in infra-red emission spectra recorded from a high spectral resolution, well calibrated and sensitive balloon instrument, the Michelson Interferometer for Passive Atmospheric Sounding, MIPAS-B2. A particular challenge is that all three species are relatively weak absorbers of infrared radiation and in the case of acetone and PAN their signatures do not exhibit significant resolved rotational structure. No remote sensing detections of PAN and acetone in the upper troposphere, as opposed to the urban boundary layer, have previously been reported in the midinfrared, perhaps also because of a previous lack of appropriate laboratory cross-sections at high spectral resolution and cold temperatures. For these gases, this work takes advantage of new laboratory measurements of the absorption cross-sections of PAN (Allen et al., 2005a,b) and acetone (Waterfall, 2003). For formic acid, Goldman et al. (1984) tentatively identified formic acid in balloon-borne solar occultation spectra and Shephard et al. (2003) and Rinsland et al. (2004) have recently reported that formic acid can be observed in ground-based solar absorption spectra. Here, we show that determination of formic acid is also possible in thermal emission, thus adding to the weight of evidence for the ability of mid-infrared instruments to measure formic acid.

\section{The MIPAS-B2}

The MIPAS-B2 instrument (Fischer and Oelhaf, 1996; Friedl-Vallon et al., 2004) is a cryogenically cooled (220$225 \mathrm{~K})$, Fourier transform, infra-red spectrometer flown on stratospheric balloons at altitudes between 29 and $39 \mathrm{~km}$. The spectrometer unit itself consists of a threemirror off-axis telescope, a Double Pendulum Interferometer and a four-channel liquid-helium-cooled detector dewar. The detectors are arsenic doped, silicon blocked impurity band detectors (Si:As BIB). A two-sided interferogram is recorded with a maximum optical path difference of $14.5 \mathrm{~cm}$, corresponding to the unapodised resolution (FWHM) of $0.04 \mathrm{~cm}^{-1}$; after apodisation with the Norton-Beer strong function (Norton and Beer, 1976, 1977), this resolution decreases to approximately $0.07 \mathrm{~cm}^{-1}$. The field of view (FOV) of the telescope gives a vertical field of view of $5.0 \mathrm{mrad}$, corresponding to approximately $3 \mathrm{~km}$ in the upper troposphere with a decreasing field of view at higher altitudes. The line of sight is controlled actively through the scan mirror based on a control loop using attitude information from an inertial navigation system aided by GPS and referenced with postflight calibration from CCD images of the night sky; an accuracy of $0.3 \mathrm{mrad}$ (40-190 $\mathrm{m}$ depending on tangent altitude) is achieved. The instrument lineshape and FOV have been characterised by laboratory measurements and also, in the case of the lineshape, through views of narrow atmospheric lines at high tangent altitudes as described by Friedl-Vallon et al. (1999).

The processing of the raw data to geo-located apodised spectra (Level 1B) is described in detail by Trieschmann (2000) and includes non-linearity and phase corrections, and apodisation prior to a Fourier transform of the resulting interferograms. Radiometric calibration is performed using instrumental gain and offset determined using the onboard blackbody reference source at instrument temperature and that of cold "space" recorded during the flight. Here "space" is defined as the spectrum recorded at a $+20^{\circ}$ elevation viewing angle; emission lines originating from molecules in the atmosphere above the balloon have to be removed from the high-resolution "space" spectrum to produce the required calibration curve. All spectra employed in this study were apodised with the Norton-Beer strong apodisation and interpolated to a sampling grid of $0.025 \mathrm{~cm}^{-1}$ using zero-filling of the measured interferogram. The apodisation is particularly useful for detection of weak cross-sectional species, such as acetone and PAN, where it is not so critical to achieve the highest spectral resolution but rather it is necessary to reduce the impact of sidelobes of multiple strong interfering spectral lines on the regions between spectral lines. This allows for a cleaner detection of the wavenumber dependence of the target spectral signatures.

The principal atmospheric spectral data sets used in this study were recorded during flight campaign 6 (Friedl-Vallon et al., 1999) where the balloon was launched from Aire sur l'Adour in Southwest France on 8 May 1998 with the instrument obtaining limb spectra over the Western Mediterranean region. The spectra analysed were all measured between 02:17 to 03:17 UTC. The Meditteranean region provides a special interest for future studies of pollution since recent studies by Holzinger et al. (2005) and Lelieveld et al. (2002) have revealed that European pollution can concentrate there with enhanced organic concentrations observed (Holzinger et al., 2005).

Profiles of atmospheric limb spectra were recorded between tangent altitudes of 7.5 and $37.9 \mathrm{~km}$ in steps of approximately $3 \mathrm{~km}$. For this study, which employed version 1 
of the Flight 6 data, averaged spectra at each tangent altitude were employed together with a standard deviation calculated from the four to twenty two individual spectra recorded at each step. Derivations of Noise Equivalent Spectral Radiance or NESR (Friedl-Vallon et al., 1999) from laboratory measurements, in-flight single scans of the internal blackbody and standard deviations of consecutive atmospheric calibrated spectra all yield similar results with typical NESR values for single spectra being $15 \mathrm{nW} /\left(\mathrm{cm}^{2} \mathrm{srcm}^{-1}\right)$ for channel $1\left(685-970 \mathrm{~cm}^{-1}\right)$ and $4.0 \mathrm{nW} /\left(\mathrm{cm}^{2} \mathrm{srcm}^{-1}\right)$ for channel $2\left(1020\right.$ to $\left.1500 \mathrm{~cm}^{-1}\right)$. For the averaged spectra employed in this study, the NESR values for the upper troposphere observations can be reduced by a factor of two (averages of four spectra) i.e. to 7.5 and $2.0 \mathrm{nW} /\left(\mathrm{cm}^{2} \mathrm{srcm}^{-1}\right)$ for channels 1 and 2 respectively. Wavenumber shifts were corrected by fitting well-known narrow lines at higher tangent altitudes. Residual errors in frequency were found to be negligible $\left(<0.0005 \mathrm{~cm}^{-1}\right)$.

\section{Detection of atmospheric signatures of weakly ab- sorbing molecules}

A number of high spectral resolution (better than $0.1 \mathrm{~cm}^{-1}$ ) instruments are currently in operation including groundbased instruments, balloon-borne instruments, aircraft-based and satellite instruments. For instruments of the MIPAS form, such as the MIPAS-B2 instrument described here and the MIPAS-E instrument on ENVISAT (Fischer and Oelhaf, 1996), the infra-red atmospheric emission spectrum observed in limb sounding reveals a rich information content with more than thirty molecules already known to contribute to observed spectra between 600 and $2400 \mathrm{~cm}^{-1}$ (16.67$4.17 \mu \mathrm{m}$ respectively). The stronger signatures of atmospheric constituents in the mid-infrared have been well observed for some time and are therefore reasonably well understood. Furthermore, infra-red radiative transfer theory is sufficiently advanced that these strong signatures can be predicted using established spectroscopic parameters, such as the HITRAN database (Rothman et al., 2003, and references therein) and modelled very well for retrieval purposes, although this is not necessarily so where line mixing or line shape effects are important or in the case of weak lines.

For weaker, cross-sectional type signatures, detection and subsequent retrieval is more complicated because it depends on the ability to model strong lines from other compounds that may partially obscure the target signatures. It also depends on the instrument performance (noise levels quantified by the NESR and calibration of the spectra). Furthermore, the presence of unsuspected or unknown signatures may give rise to additional features in the observed atmospheric spectra. Confirmation of detection in measured spectra is therefore best demonstrated by a match with expected signals, including (where possible) the detection of multiple spectral bands for the species of interest, distinctive features or the characteristic shape of such bands. Hence, the detection requires good laboratory measurements of the spectroscopy of the gas or theoretical calculations of spectroscopy (e.g. Toon et al., 1986), particularly of band/line centre frequencies and relative line intensity/cross-section variations.

In this study, we detect the signatures of PAN, acetone and formic acid in turn, showing that multiple bands, and identifiable features (band shape and Q branches) can be distinguished remarkably well. We further verify our detection methodology, and the quality of the MIPAS-B2 spectra, by showing it is possible also to represent accurately wellknown spectral signatures (HCFC-22 and CFC-12) within or close to the target spectral regions of the spectra for the three organic species considered.

\subsection{Detection methodology}

The features to be examined are relatively weak compared to the intensities of strong spectral lines of contaminants overlapping with the target features in each spectral region and in fact cannot be observed directly in measured atmospheric spectra; typically the peak strong line contributions are a factor of ten or more greater than expected PAN and acetone contributions. Therefore, in order to demonstrate spectroscopic detection via a visible spectral signature for the target gas, we seek to compare/match quantities (defined here as "residual spectra") displaying the target features in both measured and simulated equivalents rather than simply minimize the residual (ideally zero plus noise) of the measurement and its simulation. A measured residual spectrum, $\Delta Y$, is defined here as:

$\Delta Y(\tilde{v})=R_{Y}(\tilde{v})-R_{F-\mathrm{GAS}}(\tilde{v})$

where $\Delta Y$ is the measured residual spectrum as a function of wavenumber, $\tilde{v}$, and $R_{Y}$ and $R_{F}$ are the measured and simulated spectra respectively. The $R_{F-\text { GAS }}$ term describes a simulated spectrum with the target gas (GAS) excluded from the simulated atmosphere. A simulated residual spectrum, $\Delta F$, is defined here as:

$$
\Delta F(\tilde{v})=R_{F}(\tilde{v})-R_{F-G A S}(\tilde{v})
$$

Hence we see that for a perfect measurement with no associated error and for a numerically perfect simulation with accurate spectroscopic reference data and prior knowledge of all other influencing gas concentrations, then $\Delta Y$ is identical to $\Delta F$. In practice, the ability of both $\Delta Y$ and $\Delta F$ to display the spectral shape of the target molecule depends on the strength of the target signature relative to the measurement noise (for $\Delta Y)$ and the density and intensity of residual interfering features, particularly from strong spectral lines (for both $\Delta Y$ and $\Delta F$ ). Even for $\Delta F$, the appearance of residual spectral features of interfering gases is intrinsic since the presence of strong interfering gas lines alters the contribution of the target gas where the combination of these effects is non-linear, e.g. near the centre of saturating lines. In such cases, there 
will be incomplete cancellation on wavenumber scales of the order of the widths of interfering gas lines in $\Delta F$ and hence residual structure. Errors in spectroscopic data and vertical profiles of gas concentration will enhance this residual interfering structure in $\Delta Y$.

In this study, $\Delta F$ was adjusted to match $\Delta Y$ by adjusting concentration profiles of the principal atmospheric gases (see Table 1) that contribute to the observed spectrum and adjusting aerosol extinction, temperature and pressure; minor gases were included in the simulation of the spectra but their concentration profiles were not iterated. The primary means of performing this process was iteration of the expected gas concentrations and aerosol extinctions from an initial, a priori state, using Jacobian perturbation spectra scaled to match the residuals in a manner analogous to a formal inversion process but employing visual inspection of the residuals and interactive adjustment of the scaling. The Jacobian spectra were calculated as the change in the model spectrum $\left(R_{F}\right)$ for a $1 \%$ change in gas concentration at a specified altitude or a $1 \mathrm{~K}, 1 \%$ or $10^{-4} \mathrm{~km}^{-1}$ change in temperature, pressure or aerosol respectively. The spectral baseline close to each target spectral feature was a particular indicator of the quality of the fit and minimised principally using aerosol extinction (assumed spectrally flat in the vicinity of the target spectral signatures); there is also a contribution from heavy molecules such as CFC-12 and HCFC-22 for which the band shape can be fitted (Sect. 4.4). At each iteration step, i.e. after adjustment of the expected profile values, a full re-calculation of the model spectrum and Jacobians was performed to ensure accuracy in the calculated residuals. The entire process was performed at tangent altitudes from $16.44 \mathrm{~km}$ to $7.5 \mathrm{~km}$, fitting sequentially in an onion peeling type approach from higher to lower tangent altitudes; results are presented here only for altitudes where inferred concentrations were not so constrained by noise as to arise only from the initial a priori information. Mixing ratios were assumed to vary linearly between tangent altitudes.

\subsubsection{The Oxford RFM}

For the forward model, the Oxford Reference Forward Model (RFM) was employed in order to model the observed spectra measured by MIPAS-B2. The RFM is a line-by-line radiative transfer model, derived from the Genln2 model (Edwards, 1992), with the ability to simulate infra-red spectra given the instrument lineshape, field-of-view, spectroscopic parameters and atmospheric composition profiles (see http://www.atm.ox.ac.uk/RFM/ for further details). Where available, the RFM uses standard spectroscopic parameters for specified gases, in this case from the HITRAN 2000 reference database described by Rothman et al. (2003). For many other heavy cross-sectional molecules, where line parameters are not available, reference data for such molecules can be input as a special supplement to HITRAN in the form of the absorption cross-section per molecule as a function of wavenumber. For this study, cross-sectional data are taken from work by Allen et al. $(2005 \mathrm{a}, \mathrm{b})$ for PAN and from Waterfall (2003) for acetone; the acetone measurements are in preparation for a paper to be submitted shortly following which data will be submitted to the HITRAN database and also made available on request to the authors.

\subsubsection{Simulated conditions}

For initial inputs to the RFM, we use a simulated atmosphere containing those gases listed in Table 1 expected to significantly contribute (above instrument noise), including a large range of known minor species, to calculate the atmospheric spectra in the spectral range of interest for our three compounds. This simulated atmosphere was compiled in part from profiles previously retrieved from flight 6 MIPAS-B2 spectra for pressure, temperature, $\mathrm{O}_{3}$, and aerosol (Jay, 2000) and for $\mathrm{H}_{2} \mathrm{O}, \mathrm{HNO}_{3}, \mathrm{CFC}-12, \mathrm{~N}_{2} \mathrm{O}_{5}, \mathrm{~N}_{2} \mathrm{O}$, $\mathrm{CH}_{4}, \mathrm{CCl}_{4}$ and HCFC-22 (Wiegele, personal communication). Other minor species were taken from the MIPAS V3.1 reference atmospheres (Remedios, 1999) apart from some Freons (F113, F114, F115, F13 and $\mathrm{CH}_{3} \mathrm{Cl}$ ) which were developed as part of the radiative forcing study of Sihra et al. (2001), and $\mathrm{HNO}_{4}$ which was extracted from a set of reference atmospheres compiled for use in the ACECHEM study (ACECHEM, 2001). Initial profiles for PAN and acetone originated from mid-latitude values for tropospheric model calculations (Hauglustaine et al., 1998). Initial values of formic acid were based on a simple profile representation with a constant mixing ratio of $200 \mathrm{pptv}$ up to $12 \mathrm{~km}$ and a rapid decrease at higher altitudes.

\section{Detection results}

\subsection{PAN}

The PAN detection was performed using two PAN bands, one in each of two MIPAS-B2 channels. Each PAN band, one centred at $794 \mathrm{~cm}^{-1}$ (the $v_{16} \mathrm{NO}_{2}$ stretch) and the other at $1163 \mathrm{~cm}^{-1}$ (the $v_{10} \mathrm{C}-\mathrm{O}$ stretch), was fitted independently and the results compared subsequent to the fit. In all cases, the target gas, pressure, temperature, aerosol and the other principal gases in Table 1 were allowed to vary. Perturbations to initial values involved only small changes, for example, less than $10^{-3} \mathrm{~km}^{-1}$ in the simulated aerosol extinction profile. In both PAN bands, sharp residual spectral lines indicative of poorly fitted water vapour and/or ozone were reduced by iterating the comparison of $\Delta Y$ and $\Delta F$ although some strong residuals remained. Values for PAN concentrations obtained from the independent fits to the two bands were identical (less than 10 pptv difference) within the noise (see Sect. 5) and hence the same values (180 pptv and $260 \mathrm{pptv}$ at 10.4 and $7.5 \mathrm{~km}$ altitude respectively) at each tangent altitude are used in the matched spectra in Figs. 1 to 4 to show the consistency of detection in the two bands. 
Table 1. Contaminant gases used in forward modelling of the MIPAS-B2 spectra

\begin{tabular}{|c|c|c|c|c|}
\hline $\begin{array}{l}\text { Window and } \\
\text { Target Gas of } \\
\text { Interest }\end{array}$ & $\begin{array}{l}\text { Window } 1 * \text { : } \\
\text { PAN } \\
750-850 \mathrm{~cm}^{-1}\end{array}$ & $\begin{array}{l}\text { Window 2: } \\
\text { PAN } \\
1120-1330 \mathrm{~cm}^{-1}\end{array}$ & $\begin{array}{l}\text { Window 3: } \\
\text { Formic acid } \\
1060-1150 \mathrm{~cm}^{-1}\end{array}$ & $\begin{array}{l}\text { Window } 4^{*} \text { : } \\
\text { Acetone } \\
1160-1260 \mathrm{~cm}^{-1}\end{array}$ \\
\hline $\begin{array}{l}\text { Principal gases } \\
\text { in addition to } \\
\text { target gas }\end{array}$ & $\begin{array}{l}\mathrm{H}_{2} \mathrm{O}, \mathrm{CO}_{2} \\
\mathrm{CCl}_{4}, \mathrm{O}_{3}, \text { Aerosol }\end{array}$ & $\begin{array}{l}\mathrm{H}_{2} \mathrm{O}, \mathrm{CH}_{4}, \mathrm{CO}_{2}, \\
\mathrm{~N}_{2} \mathrm{O}, \mathrm{O}_{3}, \text { Aerosol, } \\
\mathrm{F} 12 *\end{array}$ & $\begin{array}{l}\mathrm{H}_{2} \mathrm{O}, \mathrm{CO}_{2}, \mathrm{O}_{3} \\
\text { Aerosol, } \mathrm{F} 12 *\end{array}$ & $\begin{array}{l}\mathrm{H}_{2} \mathrm{O}, \mathrm{CO}_{2}, \mathrm{CH}_{4} \\
\mathrm{~N}_{2} \mathrm{O}, \text { Aerosol, } \mathrm{O}_{3}\end{array}$ \\
\hline $\begin{array}{l}\text { Other } \\
\text { contributing } \\
\text { gases }\end{array}$ & $\begin{array}{l}\mathrm{C}_{2} \mathrm{H}_{2}, \mathrm{C}_{2} \mathrm{H}_{6}, \mathrm{COF}_{2}, \\
\mathrm{NH}_{3}, \mathrm{NO}_{2}, \mathrm{HNO}_{3}, \\
\mathrm{HNO}_{4}, \mathrm{~F} 11, \mathrm{~F} 113, \\
\mathrm{~F} 22^{*}, \mathrm{CH}_{3} \mathrm{Cl}, \mathrm{ClO}, \\
\mathrm{ClONO}_{2}, \mathrm{OCS}, \\
\text { acetone }\end{array}$ & $\begin{array}{l}\mathrm{COF}_{2}, \mathrm{NH}_{3}, \mathrm{SO}_{2}, \\
\mathrm{H}_{2} \mathrm{O}_{2}, \mathrm{HNO}_{3}, \mathrm{~F} 113, \\
\mathrm{~F} 114, \mathrm{~F} 115, \mathrm{~F} 13, \\
\mathrm{~F} 14, \mathrm{~F} 22, \mathrm{ClONO} \\
\mathrm{N}_{2} \mathrm{O}_{5}, \text { acetone, }\end{array}$ & $\begin{array}{l}\mathrm{NH}_{3}, \mathrm{CH}_{4}, \mathrm{~F} 115, \\
\mathrm{~F} 13, \mathrm{~F} 22, \mathrm{~N}_{2} \mathrm{O}, \\
\mathrm{SO}_{2}, \mathrm{~F} 113, \mathrm{~F} 114, \\
\text { PAN, F11, OCS }\end{array}$ & $\begin{array}{l}\mathrm{COF}_{2}, \mathrm{SO}_{2}, \mathrm{H}_{2} \mathrm{O}_{2} \\
\mathrm{HNO}_{3}, \mathrm{~F} 11, \mathrm{~F}_{2} *, \\
\mathrm{~F} 14, \mathrm{~F} 22, \mathrm{ClONO}_{2}, \\
\mathrm{~N}_{2} \mathrm{O}_{5}, \mathrm{PAN}, \mathrm{HNO}_{4}, \\
\mathrm{HNO}_{3}\end{array}$ \\
\hline
\end{tabular}

* N.B. In a separate verification test (Sect. 4.4), the F22 and F12 signatures were investigated in windows 1 and 4 respectively.

For the $794 \mathrm{~cm}^{-1}$ band, the PAN feature was compared between $\Delta Y$ and $\Delta F$ principally in the $785-805 \mathrm{~cm}^{-1}$ region; the principal "baseline" regions were selected to be $750-770 \mathrm{~cm}^{-1}, 820-830 \mathrm{~cm}^{-1}$ and $840-850 \mathrm{~cm}^{-1}$. Two additional features that were checked closely in the fits were the $\mathrm{CCl}_{4}$ peak contributions between 790 and $800 \mathrm{~cm}^{-1}$ and also near $780 \mathrm{~cm}^{-1}$, and the intensity and width of the temperature and pressure-sensitive $\mathrm{CO}_{2} v_{2}$ Q-branch between 792 and $793 \mathrm{~cm}^{-1}$. For $\mathrm{CCl}_{4}$, the initial profile had to be scaled downwards, for example, from $118 \mathrm{pptv}$ to $100 \mathrm{pptv}$ at $10.4 \mathrm{~km}$, a result which is very consistent with $\mathrm{CCl}_{4}$ mixing ratios of 102 pptv reported for 1998 by Montzka et al. (1999). For the $\mathrm{CO}_{2} \mathrm{Q}$ branch, small adjustments of pressure and temperature improved the fit at this frequency but small residuals remained even with inclusion of line mixing. Refined retrieval schemes (as opposed to detection as shown here) could choose to exclude the intense $\mathrm{CO}_{2} \mathrm{Q}$ branch from the fit (see Sect. 5).

For the $1163 \mathrm{~cm}^{-1}$ band, the PAN feature is more symmetric in information content so that the PAN spectral shape clearly emerges over a range of approximately $10 \mathrm{~cm}^{-1}$ either side of $1163 \mathrm{~cm}^{-1}$. Nonetheless, the region between $1155-1164 \mathrm{~cm}^{-1}$ and the region near $1167 \mathrm{~cm}^{-1}$ are particularly sensitive to PAN emissions. The baseline was fitted between 1120 and $1140 \mathrm{~cm}^{-1}$ primarily, and some information is also available between 1180 and $1300 \mathrm{~cm}^{-1}$ as can be seen from the acetone fits. As for the $794 \mathrm{~cm}^{-1}$ band, residual water vapour lines are the chief problem but there is also some structure due to $\mathrm{N}_{2} \mathrm{O}$ lines. The spectral noise is lower for the $1163 \mathrm{~cm}^{-1}$ band which is useful although not a limiting factor in the detection of PAN.

The values of PAN derived from this MIPAS balloon flight compare reasonably with observations and models of midlatitude, upper troposphere concentrations. Aircraft mea- surements of PAN observed in the UT show mixing ratios which vary strongly from less than 100 pptv (e.g. Emmons et al., 2000) to greater than 300 pptv (e.g. Russo et al., 2003; Miyazaki et al., 2003). Effects which can play a role include warm conveyor belt and convective outflow processes transporting air from industrial or biomass burning regions (Holzinger et al., 2005; Miyazaki et al., 2003). Model calculations indicate mean mid-latitude mixing ratios of close to 100 pptv at these altitudes but PAN concentrations are dependent on photolysis rates for acetone and isoprene emissions (Arnold et al., 2005), as well as the dynamical processes already noted. Wang et al. (1998) show enhancements in PAN levels above Europe compared to measurements over the Atlantic and it is possible that springtime in the Northern midlatitudes results in increased values of PAN at the altitudes of the observations of flight 6 compared to average mid-latitude concentrations.

\subsection{Acetone}

For acetone, only the $v_{17} \mathrm{C}-\mathrm{C}$ stretch at $1216 \mathrm{~cm}^{-1}$ is potentially observable according to radiative transfer simulations. The detection of acetone is one of the more difficult problems in analysing the Flight 6 MIPAS balloon spectra, because of the concentrations of acetone most likely sampled during this mid-latitude flight, and the relatively weak acetone absorption cross-section. The acetone spectral region suffers from competing spectral features due to a number of interfering gases leading to a heavily distorted spectral signature for acetone (compared to a pure band shape) in the residual spectra $(\Delta Y, \Delta F)$. In addition, the strength of the water vapour lines causes saturation of the higher wavenumber part of the spectral region. Figure 5 shows results from the MIPAS-B2 analysis at $10.4 \mathrm{~km}$ altitude; at $7.5 \mathrm{~km}$, errors from water vapour 


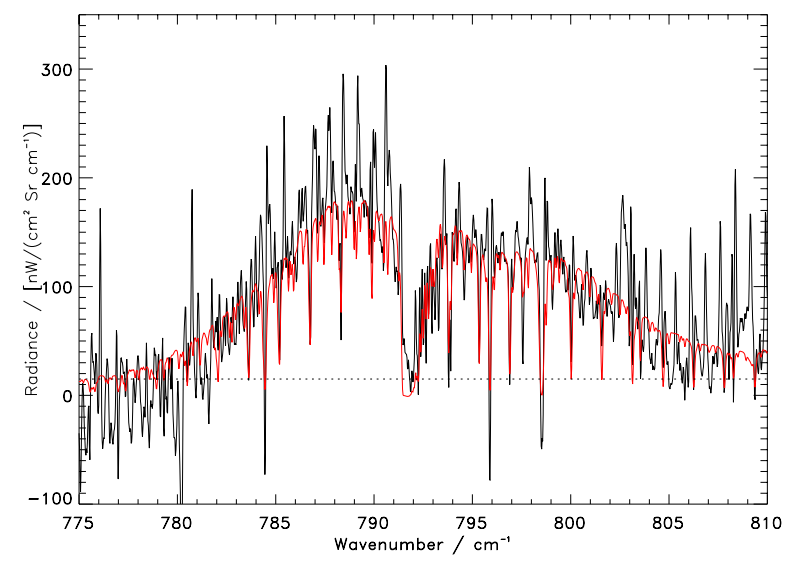

Fig. 1. PAN detection, $794 \mathrm{~cm}^{-1}$ band, $10.4 \mathrm{~km}$ tangent altitude. A comparison of measured residual, $\Delta Y$ (black), with simulated residual, $\Delta F$ (red), for a measurement (channel 1) recorded during the MIPAS-B2 Flight 6 . The simulated residual is shown for a PAN concentration of $180 \mathrm{pptv}$ at this altitude.

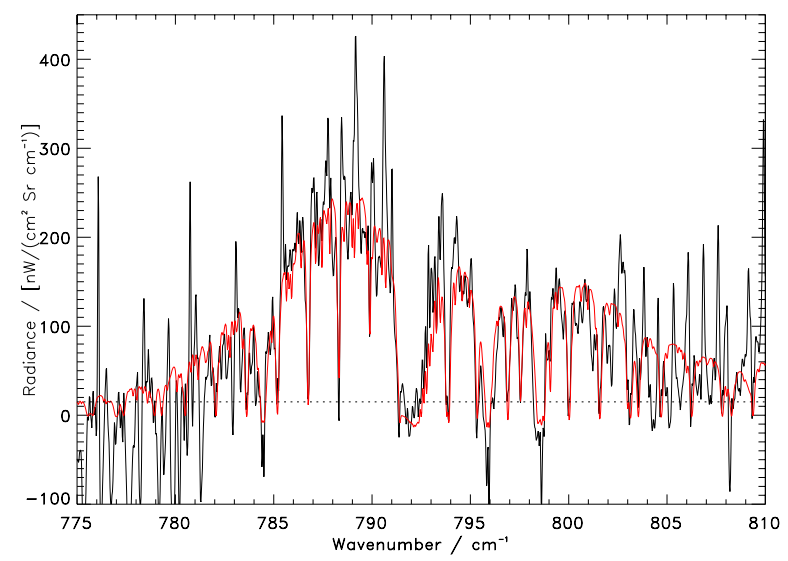

Fig. 2. PAN detection, $794 \mathrm{~cm}^{-1}$ band, $7.5 \mathrm{~km}$ tangent altitude. A comparison of measured residual, $\Delta Y$ (black), with simulated residual, $\Delta F$ (red), for a measurement (channel 1) recorded during the MIPAS-B2 Flight 6 . The simulated residual is shown for a PAN concentration of $260 \mathrm{pptv}$ at this altitude.

(including its continuum) and the other interfering gases renders acetone detection difficult with the data from this flight. The higher wavenumber region above $1240 \mathrm{~cm}^{-1}$ is close to saturation so that information on aerosol is obtained from the lower wavenumber portion below the acetone feature; in effect the aerosol information is translated from the PAN retrieval. The acetone spectral feature in the residual spectra is split into four distinct windows, each of which is separated by features due to interfering trace gases. Hence, although the overall band shape is difficult to identify, the agreement between $\Delta Y$ and $\Delta F$ in the four windows is very good and shows the utility of the detection methodology for weak spectral signatures.

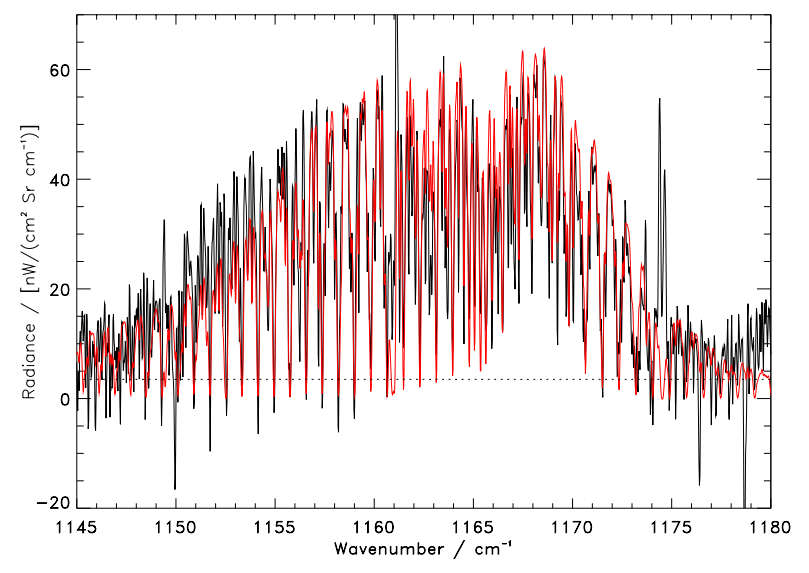

Fig. 3. PAN detection, $1163 \mathrm{~cm}^{-1}$ band, $10.4 \mathrm{~km}$ tangent altitude. A comparison of measured residual, $\Delta Y$ (black), with simulated residual, $\Delta F$ (red), for a measurement (channel 2) recorded during the MIPAS-B2 Flight 6 . The simulated residual is shown for a PAN concentration of $180 \mathrm{pptv}$ at this altitude.

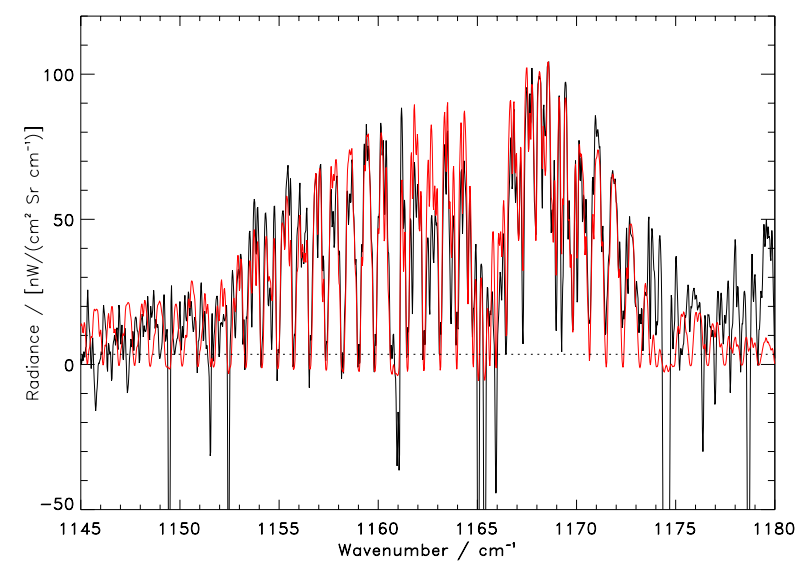

Fig. 4. PAN detection, $1163 \mathrm{~cm}^{-1}$ band, $7.5 \mathrm{~km}$ tangent altitude. A comparison of measured residual, $\Delta Y$ (black), with simulated residual, $\Delta F$ (red), for a measurement (channel 2) recorded during the MIPAS-B2 Flight 6 . The simulated residual is shown for a PAN concentration of $260 \mathrm{pptv}$ at this altitude.

The spectra of flight 6 are consistent with 530 pptv of acetone present at $10.4 \mathrm{~km}$ altitude. This inferred concentration is comparable to the latest model calculations for acetone (Arnold et al., 2005) which predict higher concentrations of acetone in the upper troposphere using new photolysis rates (Arnold et al., 2004; Blitz et al., 2004) than had been the case for earlier budget studies (Jacob et al., 2002). The value is also within the range of aircraft composite profiles shown, for example, in Horowitz et al. (2003) particularly those from the SONEX campaign. 


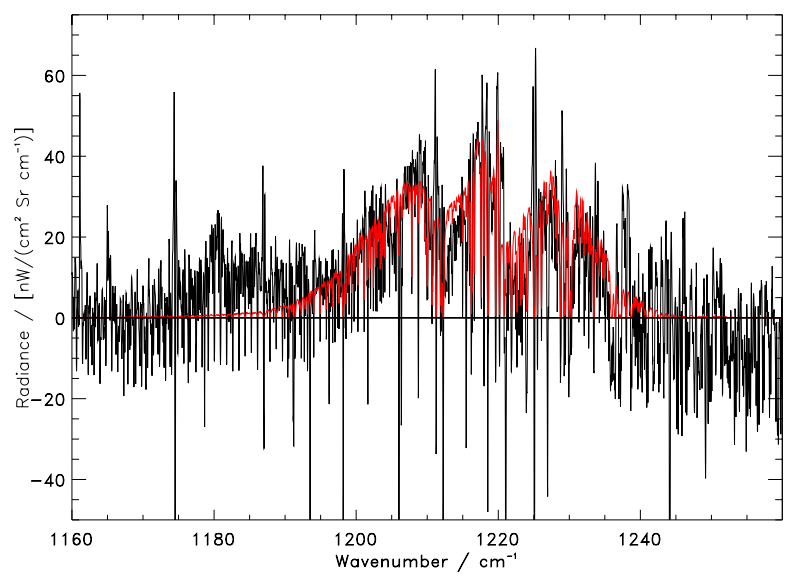

Fig. 5. Acetone detection, $1220 \mathrm{~cm}^{-1}$ band, $10.4 \mathrm{~km}$ tangent altitude. A comparison of measured residual, $\Delta Y$ (black), with simulated residual, $\Delta F$ (red), for a measurement (channel 1) recorded during the MIPAS-B2 Flight 6 . The simulated residual is shown for an acetone concentration of 530 pptv at this altitude.

\subsection{Formic acid}

For formic acid, forward model sensitivity calculations indicated that only one band, the $v_{6}$ band centred at $1105 \mathrm{~cm}^{-1}$, is potentially observable. This band features an intense and distinctive $\mathrm{Q}$ branch which has been noted by Goldman et al. (1984) as being a characteristic of the appearance of a formic acid signature in atmospheric spectra. Fortunately, the atmospheric spectrum in the region of the $v_{6}$ formic acid band is much less complicated than the corresponding regions for PAN and acetone since ozone is the only major trace species contributing to the region. Lines from $\mathrm{H}_{2} \mathrm{O}$ and its isotope, $\mathrm{HDO}$, as well as from $\mathrm{CH}_{4}$ are present in this Q branch spectral region and could affect the detection. However, at these altitudes in the mid-latitudes, their relative contribution is expected to be small. The essential parameters for the fit to the spectral region for formic acid therefore included formic acid, ozone and aerosol. The baseline was fitted for aerosol principally between 1060 and $1080 \mathrm{~cm}^{-1}$ since the spectral influence of PAN becomes important beyond $1145 \mathrm{~cm}^{-1}$ on the other side of the band. Results for the fit are shown in Fig. 6 for a tangent altitude of $10.4 \mathrm{~km}$. The Q branch feature is clear and fits well with previous observations such as those reported by Shephard et al. (2003). It is also possible to distinguish the overall shapes of the $\mathrm{P}$ and $\mathrm{R}$ branches, although not their structures, especially given the confidence of successful matching of the signature of CFC-12 in channel 2. At $7.5 \mathrm{~km}$, the formic acid Q branch remains a clearly identifiable feature but residual structure causes problems in interpreting the comparison in the $\mathrm{P}$ and $\mathrm{R}$ branches (Fig. 7), particularly in the baseline near $1130 \mathrm{~cm}^{-1}$ and ozone lines between 1060 and $1090 \mathrm{~cm}^{-1}$. The strongest evidence for the formic acid detection therefore comes from the spectra at $10.4 \mathrm{~km}$ tangent altitude.

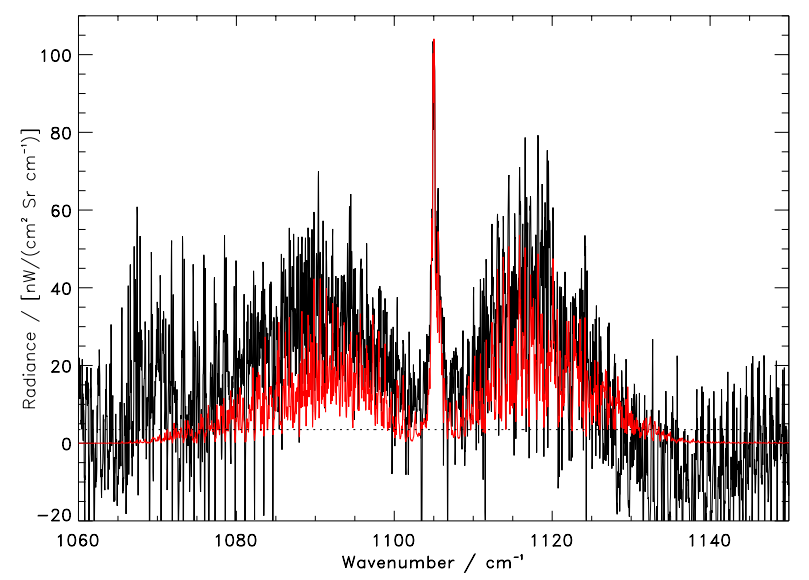

Fig. 6. Formic acid detection, $1105 \mathrm{~cm}^{-1}$ band, $10.4 \mathrm{~km}$ tangent height. A comparison of measured residual, $\Delta Y$ (black), with simulated residual, $\Delta F$ (red), for a measurement (channel 2) recorded during the MIPAS-B2 Flight 6 . The simulated residual is shown for a formic acid concentration of 200 pptv at this altitude.

The spectra of flight 6 are consistent with formic acid concentrations of $320 \mathrm{pptv}$ at $7.5 \mathrm{~km}$ and $200 \mathrm{pptv}$ at $10.4 \mathrm{~km}$ using HITRAN 2000 spectroscopy. Recent research (Vander Auwera, 2006) indicates that HITRAN 2000 absolute intensities could be low by nearly a factor of two which would lead to a corresponding decrease in the inferred formic acid to $50 \%$ of the quoted values; see Sect. 5 for further discussion. Aircraft measurements of formic acid concentrations vary even more strongly than those for PAN, ranging from 60 pptv to nearly 600 pptv (e.g. Singh et al., 2000; Reiner et al., 1999). Hence both the inferred values using HITRAN 2000 and a reduced set of values would fall within the range of previous observations. Standard chemical transport models of formic acid tend to underestimate severely aircraft observations, e.g. von Kuhlmann (2003), as for other oxygenates, so it is not possible to compare models with the observations made here. However, the model problems clearly indicate that global measurements of formic acid are highly desirable, as would potentially be obtainable from infra-red satellite measurements.

\subsection{Verification of the detection methodology with well- known spectral features}

It is possible to verify the fundamentals of the detection methodology employed above by investigating the appearance in the residual spectra of well-known spectral signatures. The infra-red bands of HCFC-22 and CFC-12 are ideal for this purpose since their concentrations at upper tropospheric altitudes are relatively well-known, each spectral band contains a sharp, strong $\mathrm{Q}$ branch which is readily identifiable, and the cross-sectional $\mathrm{P}$ and $\mathrm{R}$ branches provide a testable band shape over the appropriate range of signals. One such spectral feature was investigated in each of the 


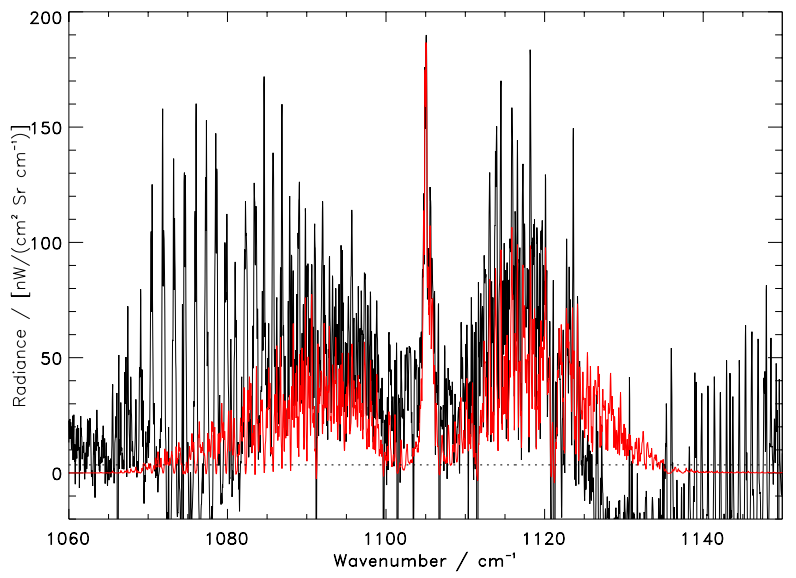

Fig. 7. Formic acid detection, $1105 \mathrm{~cm}^{-1}$ band, $7.5 \mathrm{~km}$ tangent altitude. A comparison of measured residual, $\Delta Y$ (black), with simulated residual, $\Delta F$ (red), for a measurement (channel 2) recorded during the MIPAS-B2 Flight 6 . The simulated residual is shown for a formic acid concentration of 320 pptv at this altitude.

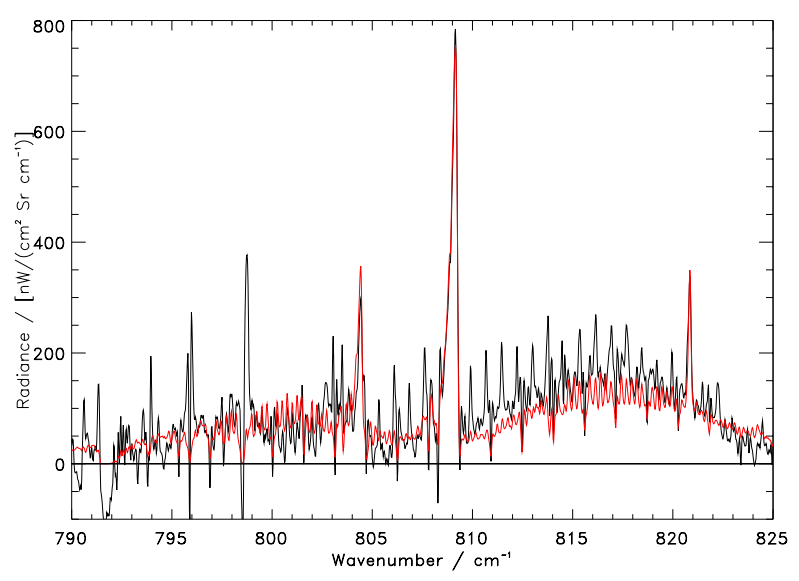

Fig. 8. HCFC-22 detection, $809 \mathrm{~cm}^{-1}$ band, $10.4 \mathrm{~km}$ tangent altitude. A comparison of measured residual, $\Delta Y$ (black), with simulated residual, $\Delta F$ (red), for a measurement (channel 1) recorded during the MIPAS-B2 Flight 6 . The simulated residual is shown for a HCFC-22 concentration of 135 pptv at this altitude.

MIPAS-B2 channels: HCFC-22 for channel 1 and CFC-12 for channel 2. The purpose was to show that a comparison of $\Delta Y$ and $\Delta F$ did in fact reveal the requisite spectral signature for the well-mixed gases, as expected, at signal levels commensurate with the anticipated PAN, acetone and formic acid contributions to the spectra.

Figure 8 shows a comparison of $\Delta Y$ and $\Delta F$ computed with HCFC-22 as the target gas at $10.4 \mathrm{~km}$ tangent altitude, examining in particular the spectral region between 805 and $825 \mathrm{~cm}^{-1}$ which contains the $\nu_{7}$ band centred at $809 \mathrm{~cm}^{-1}$. The gases listed for window 1 in Table 1 were included in the calculations with PAN values assumed from the fits described in Sect. 4.1 although its contribution is small in

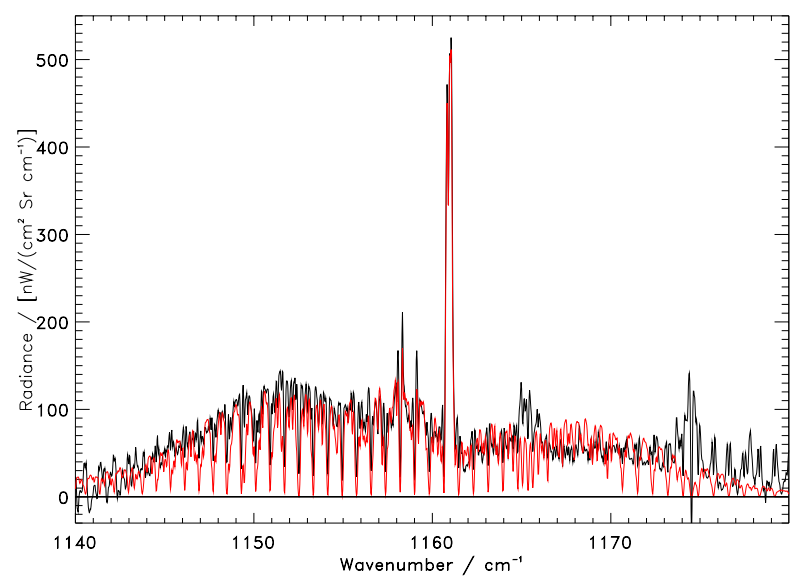

Fig. 9. CFC-12 detection, $1161 \mathrm{~cm}^{-1}$ band, $10.4 \mathrm{~km}$ tangent altitude. A comparison of measured residual, $\Delta Y$ (black), with simulated residual, $\Delta F$ (red), for a measurement (channel 2) recorded during the MIPAS-B2 Flight 6 . The simulated residual is shown for a CFC-12 concentration of 545 pptv at this altitude.

the target region for HCFC-22. The plot is shown for an HCFC-22 concentration of 135 pptv which was not iterated since it immediately provided a very good fit of $\Delta F$ to $\Delta Y$. The $\mathrm{Q}$ branch near $809 \mathrm{~cm}^{-1}$ is relatively strong, compared to the organic compound spectral features of interest here, but of greater relevance is the very good fit to the $\mathrm{P}$ and $\mathrm{R}$ branches which range in intensity from zero up to approximately $100 \mathrm{nW} /\left(\mathrm{cm}^{2} \mathrm{srcm}^{-1}\right)$. The structure observed, particularly in the $\mathrm{R}$ branch, is due to intrinsic incomplete subtraction of stronger $\mathrm{CO}_{2}$ gas lines. The quality of the fit in $\Delta Y$ and $\Delta F$ clearly lends confidence to the results for the detection of PAN as described in Sect. 5 below.

Figure 9 shows the result for a similar exercise using channel 2 spectra to detect the spectral signature of CFC-12 at the same tangent altitude of $10.4 \mathrm{~km}$. The target signature is the $v_{6}$ band of CFC-12 (centred at $1161 \mathrm{~cm}^{-1}$ ) between 1140 and $1180 \mathrm{~cm}^{-1}$. The concentration employed in the comparison shown is $545 \mathrm{pptv}$ which is in excellent agreement with the IPCC estimate of 533 pptv for 1998 (IPCC, 2001; Montzka et al., 1999). As for HCFC-22, the $\mathrm{Q}$ branch is reasonably intense with peak signals reaching over $500 \mathrm{nW} /\left(\mathrm{cm}^{2} \mathrm{srcm}^{-1}\right)$ but the $\mathrm{P}$ and $\mathrm{R}$ branches are of weaker signal level. The agreement in all 3 branches, $\mathrm{P}$, $\mathrm{Q}$ and $\mathrm{R}$ is excellent and very encouraging in terms of the ability to determine and fit weak signatures in MIPAS-B2 spectra, particularly those in channel 2 such as the signature due to acetone. The fits to the $\mathrm{Q}$ branches in both channels demonstrate that detection of $\mathrm{Q}$ branches, e.g. for formic acid, should be possible although dependent on the scale and proximity of residual line structure. 


\subsection{Summary of detection results}

The results in this section have demonstrated the spectroscopic detection of PAN, acetone and formic acid in the MIPAS-B2 flight 6 spectra for the mid-latitude upper troposphere; results are most likely applicable to the upper troposphere outside of the tropics given the variabilities of the relevant interfering gases. A natural consequence of the result is that the concentrations of these gases have also been deduced as part of the detection process. Results for the three gases are summarised in Fig. 10 which shows the final geophysical data together with estimated error bars (see Sect. 5) as a function of altitude.

\section{Chief error sources and implications}

In addition to the identification of a spectral signature of target molecules, it is interesting to consider some of the chief error sources in derived concentrations which are relevant to the detection and also indicate the feasibility of retrievals from MIPAS-type instruments in the future. The detection analysis of Sect. 4 in effect uses reduced spectral windows to infer concentrations of the target gas and the fit to an entire spectral region to improve the fit to features due to interfering species. In the error analysis here, a number of scenarios are presented which are illustrative of two theoretical contrasting cases and the detection case: (1) theoretical error arising from use of reduced spectral windows to fit the target gas and aerosol jointly but with interferences estimated from independent studies; (2) theoretical error arising from the use of one large spectral interval with joint retrieval of target gas, aerosol and the major interfering species; (3) a conservative estimate of error, appropriate to the detections in this paper, in which errors are estimated as in (1) with the reduced spectral windows but with smaller errors assigned to interfering species through the use of fitting elsewhere in the broad spectral region of case (2). The case (3) estimate is necessarily an approximation to the errors associated with the detection process as it must account for the fact that whilst the interferences are adjusted as part of the fit, residuals in the spectra indicate some remaining uncertainties in the parameter values above that expected from a theoretical joint retrieval. It is expected that refinements to retrieval schemes and optimisation for operational retrievals could in principle deliver improved performance over any of the three cases discussed here and this analysis identifies some of the geophysical factors which limit retrieval performance. Error estimates in this paper are therefore likely to be conservative compared to ultimate performance of an optimised retrieval scheme. The analysis is performed for the observations at $10.4 \mathrm{~km}$ tangent altitude since this is common to all three molecules.

The errors considered here have been estimated using the error characterisation for MIPAS type instruments given in Dudhia et al. (2002), where the errors are considered to be

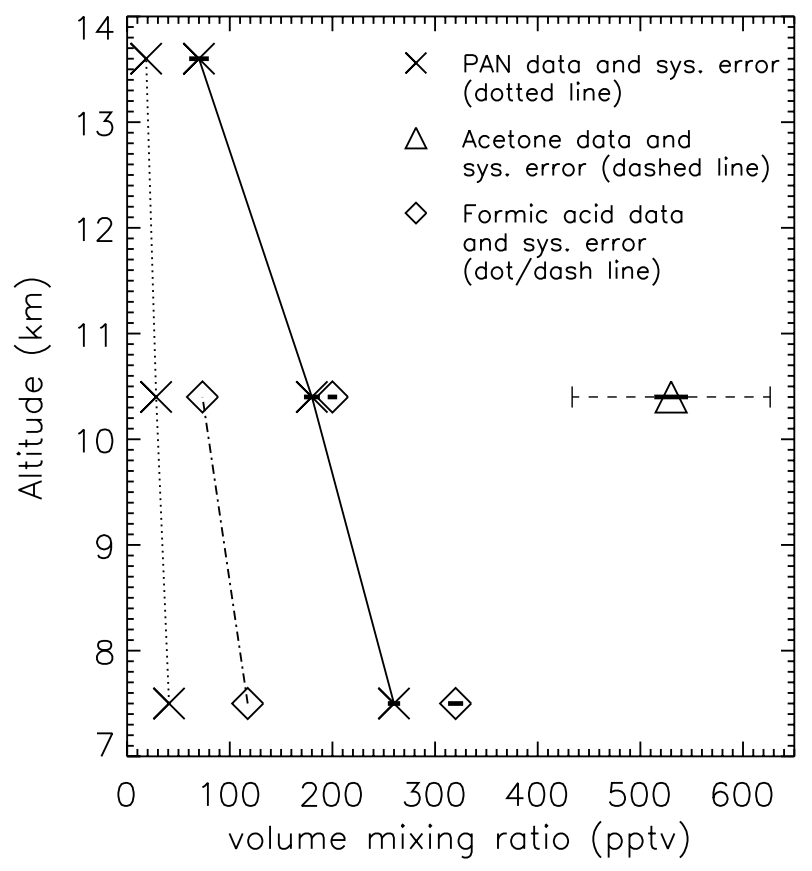

Fig. 10. Inferred concentrations for PAN, acetone and formic acid as a function of altitude (MIPAS-B2 flight 6). Error bars are estimated for the detection method (case(3)) as described in Sect. 5 (channel 1 only for the PAN profile plot). Systematic errors are shown as the dotted line for PAN, dot-dash line for formic acid and dashed line (horizontal error bar) for the acetone point. Random errors are indicated by thick horizontal lines and arise from the noise equivalent spectral radiance at each altitude.

potentially fully correlated in frequency for the systematic errors and fully uncorrelated for the random errors. In this study, the error matrices and their sub-elements are computed at one altitude, $z$, only as an approximation to the detection process and therefore the errors are conservative compared to those that might be obtained for a fit to the entire vertical profile in one step; vertical profile correlations are not present in the error estimation since the elements are computed for one altitude alone. The random error is expressed for one altitude alone as:

$\mathbf{S}_{x}^{\mathrm{rnd}}(z)=\mathbf{G}(z) \mathbf{S}_{Y}(z) \mathbf{G}^{T}(z)$

where $\mathbf{S}_{x}^{\text {rnd }}$ is the random error covariance of a retrieved profile, $\boldsymbol{x}$, at altitude $z, \mathbf{S}_{Y}$ is the random noise covariance of the measured spectrum at $z$, and $\mathbf{G}$ is a gain matrix associated with the detection process and evaluated at $z$.

The corresponding systematic error at altitude $z$ is:

$\mathbf{S}_{x}^{\text {sys }}(z)=\Sigma \mathbf{G}(z) \mathbf{S}_{Y}^{i}(z) \mathbf{G}^{T}(z)$

where:

$\mathbf{S}_{Y}^{i}(z)=\left(\Delta Y_{\mathrm{sys}}^{i}(z)\right)\left(\Delta Y_{\mathrm{sys}}^{i}(z)\right)^{T}$

and each of the $\Delta Y_{\text {sys }}^{i}$ is a fully wavenumber-correlated error spectrum at the altitude $z$ for the corresponding systematic 
error. Since the detection method incorporates an effective a priori profile through the initial guess, which in this method constrains both expected values and profile shapes, the gain matrix for detection is estimated formally using the optimal estimation approach (Rodgers, 2000):

$\mathbf{G}(z)=\mathbf{S}_{a}(z) \mathbf{K}^{T}(z)\left[\mathbf{S}_{Y}(z)+\mathbf{K}(z) \mathbf{S}_{a}(z) \mathbf{K}^{T}(z)\right]^{-1}$

where $\mathbf{S}_{a}$ is the a priori covariance matrix at $z$ and $\mathbf{K}$ is the Jacobian for the altitude of detection, $z$, i.e. $\mathbf{K}(z)=\delta R_{Y}(z) / \delta x \approx \delta R_{F}(z) / \delta x$. In case (1) and case (3), the gain matrix and subsequent errors have been calculated for a joint retrieval of the target molecule and aerosol which were the major "retrieved" species in this study. The a priori error for each target gas retrieval was set to be $100 \%$ which is consistent with the fitting approach and the expected variations in derived target gas concentrations from initial to final concentrations for this flight. The a priori aerosol profile error was set to $10^{-2} \mathrm{~km}^{-1}$ and is assumed to be retrived jointly from the same spectral window as the target gas thus minimising errors due to spectral dependence of aerosol. In case (2) all the major interfering species are assumed to be retrieved simultaneously with the target gas and aerosol; a priori errors for the interfering gases are set to the estimated errors for these species from independent studies as employed in case (1) and described next.

Estimates of uncertainties in pressure, temperature and interfering species can be derived from a number of sources. Pressure and temperature errors have been taken to be $4 \%$ and $1 \mathrm{~K}$ with ozone uncertainties of $10 \%$ based on the study by Jay (2000). Water vapour errors have been conservatively set to $50 \%$ since the accuracy of water vapour retrievals tends to be lower in the upper troposphere; $10 \%$ is more typical for MIPAS-B total errors (one sigma) in the lower stratosphere for $\mathrm{H}_{2} \mathrm{O}$ (Stowasser et al., 1999) and for $\mathrm{N}_{2} \mathrm{O}$ and $\mathrm{CH}_{4}$ at all altitudes. Errors for $\mathrm{CCl}_{4}$ and $\mathrm{CFC}-12$ have been set to $5 \%$. The $\mathrm{CCl}_{4}$ values had to be adjusted by $18 \%$ in the fit but the result was consistent to better than 5\% with Montzka et al. (1999), as noted in Sect. 4.1. Similarly the CFC-12 value agreed to better than 5\% with Montzka et al. (1999), as noted in Sect. 4.4. An error of 5\% is therefore considered reasonable for the mixing ratio errors assigned to these two gases. Uncertainties for other gases have been assessed from the MIPAS standard atmospheres (Remedios, 1999) which contain maximum, minimum and one sigma errors. Essentially their contributions are negligible compared to the specific errors already described.

For the detection process estimated in case (3), the errors due to these interfering sources are reduced to account for the adjustments of these parameters performed as part of the fitting process. What matters for this purpose is mostly that spectral features are fitted well in which case errors in parameters such as absolute intensity will be compensated by errors in determined concentrations and the net effect on target gas retrievals will be negligible; for pressure and temperature, however, there will also be an error through estima- tion of line-of-sight mass and Planck function. Based on the quality of the fits, pressure errors were estimated to be less than $1 \%$ from the $\mathrm{CO}_{2}$ lines with temperature and $\mathrm{CO}_{2}$ uncertainties remaining of the order of $1 \mathrm{~K}$ and $1 \%$ respectively, water vapour errors were estimated to be $20 \%$ with some evidence of difficulties in fitting the measured lines possibly due to non-Voigt lineshape behaviour (P. Bernath, personal communication), and errors for $\mathrm{CH}_{4}, \mathrm{~N}_{2} \mathrm{O}$ and $\mathrm{O}_{3}$ reduced to $5 \%$. The CFC-12 and HCFC-22 features are fitted particularly well (Sect. 4.4) and a residual error of $2 \%$ is therefore considered reasonable. For $\mathrm{CCl}_{4}$, the fit quality is linked with that for PAN and conservatively the $\mathrm{CCl}_{4}$ error has not been reduced below $5 \%$.

Spectroscopic errors are of the order of $10 \%$ for PAN and acetone. For formic acid, an intensity error of close to $15 \%$ is suggested by Perrin et al. (1999) accounting for uncertainties in dimer formation in the lab measurements. However, as noted in Sect. 4.3, recent investigations have suggested the possibility of a factor of two underestimation of absolute intensity in the HITRAN database (Vander Auwera, 2006). Hence, first of all it is to be noted in this study that formic acid concentrations are those derived with HITRAN 2000 spectroscopy. Secondly, it is important to note that the chief spectroscopic errors for all three gases are systematic and largely wavenumber independent. Therefore they do not profoundly affect the detection nor the percentage errors given in Tables 2 to 5. In the error calculations presented here, we therefore adopt a $15 \%$ uncertainty in formic acid spectroscopy for detection and future retrieval assessments but always note that the absolute intensity question needs to be resolved for the full potential absolute accuracy of formic acid mixing ratios to be achieved in the future.

For the fits shown in Figs. 1 to 4 respectively, most of the information used to deduce PAN was derived from a split PAN spectral window of $785-790 \mathrm{~cm}^{-1}$ and $795-805 \mathrm{~cm}^{-1}$ in window 1 and $1150-1170 \mathrm{~cm}^{-1}$ in window 3 respectively; the corresponding broad spectral ranges were 775 to $810 \mathrm{~cm}^{-1}$ and 1145 to $1180 \mathrm{~cm}^{-1}$. Estimated error sources for the two PAN bands are shown in Table 2 and Table 3 for the $10.4 \mathrm{~km}$ tangent altitude case. For both PAN bands, as indeed for all the spectral signatures studied here, the temperature and pressure errors are important. The major difference between the sensitivity of the two individual band retrievals is the effect of interfering gases on the errors for the lower wavenumber band. The ability to retrieve water vapour in the upper troposphere or to accurately model water vapour effects is a limiting factor in utilisation of the $794 \mathrm{~cm}^{-1}$ band. Knowledge of $\mathrm{CCl}_{4}$ is also important. Retrievals from the $1163 \mathrm{~cm}^{-1}$ band are limited by systematic errors. Overall, the utility of both bands is clearly demonstrated and the estimated errors close to $15 \%$ from each band support the detection evidence provided in Sect. 4.1. The prospects for good PAN retrievals from future balloon or globally from satellite remote sensing instruments seem excellent. 
Table 2. Chief error sources for PAN at $10.4 \mathrm{~km}$ tangent altitude, $794 \mathrm{~cm}^{-1}$ PAN band, channel 1. Case (1): joint PAN/aerosol retrieval from 785 to $790 \mathrm{~cm}^{-1}$ and 795 to $805 \mathrm{~cm}^{-1}$, case (2): joint PAN/aerosol/interfering species retrieved from 775 to $810 \mathrm{~cm}^{-1}$, case (3): estimated error for detection methodology in this paper.

\begin{tabular}{llll}
\hline Error source & Case (1) error (\%) & Case (2) error (\%) & Case (3) error (\%) \\
\hline Temperature $(1 \mathrm{~K}, 1 \mathrm{~K})$ & 4.7 & - & 4.7 \\
Pressure $(4 \%, 1 \%)$ & 21.3 & - & 5.3 \\
$\mathrm{H}_{2} \mathrm{O}(50 \%, 20 \%)$ & 17.8 & - & 7.1 \\
$\mathrm{CCl}_{4}(5 \%, 5 \%)$ & 6.7 & - & 6.7 \\
$\mathrm{CO}_{2}(1 \%, 1 \%)$ & 0.2 & - & 0.2 \\
Spectroscopy $(10 \%)$ & 10.0 & 10.0 & 10.0 \\
Total systematic (RSS) & 30.6 & - & 15.7 \\
Random errors (noise) & 4.3 & 2.2 & 4.3 \\
Total accuracy & 30.9 & 10.2 & 16.3 \\
\hline
\end{tabular}

Table 3. Chief error sources for PAN at $10.4 \mathrm{~km}$ tangent altitude, $1163 \mathrm{~cm}^{-1}$ PAN band, channel 2. Case (1): joint PAN/aerosol retrieval from 1150 to $1170 \mathrm{~cm}^{-1}$, case (2): joint PAN/aerosol/interfering species retrieved from 1145 to $1180 \mathrm{~cm}^{-1}$, case (3): estimated error for detection methodology in this paper.

\begin{tabular}{llll}
\hline Error source & Case (1) error (\%) & Case (2) error (\%) & Case (3) error (\%) \\
\hline Temperature $(1 \mathrm{~K}, 1 \mathrm{~K})$ & 6.5 & - & 6.5 \\
Pressure $(4 \%, 1 \%)$ & 13.5 & - & 3.4 \\
$\mathrm{H}_{2} \mathrm{O}(50 \%, 20 \%)$ & 4.4 & - & 1.8 \\
$\mathrm{~N}_{2} \mathrm{O}(10 \%, 5 \%)$ & 3.4 & - & 1.7 \\
$\mathrm{CH}_{4}(10 \%, 5 \%)$ & 1.5 & - & 0.8 \\
$\mathrm{CFC}-12(5 \%, 2 \%)$ & 2.7 & - & 1.1 \\
Spectroscopy (10\%) & 10.0 & 10.0 & 10.0 \\
Total systematic (RSS) & 19.1 & - & 12.7 \\
Random errors (noise) & 4.0 & 2.2 & 4.0 \\
Total accuracy & 19.5 & 10.2 & 13.3 \\
\hline
\end{tabular}

Acetone errors were estimated using the reduced spectral range 1216 to $1220 \mathrm{~cm}^{-1}$ and 1221 to $1234 \mathrm{~cm}^{-1}$ and the broad spectral range from 1160 to $1260 \mathrm{~cm}^{-1}$. Acetone determination shows the greatest dependence on water vapour of all the organic species considered here and also depends considerably on the accuracy of $\mathrm{N}_{2} \mathrm{O}$ data. These findings are consistent with the detection results in the previous section and indeed it is the acetone detection which proves to be most difficult at the lower tangent altitude of $7.5 \mathrm{~km}$ due to a rapid increase in errors due to $\mathrm{H}_{2} \mathrm{O}$. Retrievals of acetone in the tropics may well prove to be difficult. For the case considered here, it is clearly the systematic errors that dominate rather than random errors. For general mid-latitude retrievals, an accuracy of even $30 \%$ would still be very useful given the paucity of measurements of acetone.

A narrow spectral region of 1104.5 to $1106 \mathrm{~cm}^{-1}$ was used to investigate the formic acid retrieval based on the definitive detection and clarity of the $\mathrm{Q}$ branch and the considerable interference from other gases in both the $\mathrm{P}$ and $\mathrm{R}$ branches which can be seen in Figs. 6 and 7; the broad spectral range tested extended from 1060 to $1150 \mathrm{~cm}^{-1}$. Essentially temperature and pressure errors dominate the error budget and lead to considerable error in the retrieval. Hence this retrieval will place the most stringent requirements on knowledge of these two quantities. In addition, the spectroscopic error is important. If there are errors also in intensities, as discussed above, then it will be important for these to be resolved in order for absolute values of formic acid to be retrievable. In other respects, the error budget does not indicate particular problems with detection but rather with sufficient knowledge of input parameters for accurate retrievals. 
Table 4. Chief error sources for acetone at $10.4 \mathrm{~km}$ tangent altitude, channel 2. Case (1): joint acetone/aerosol retrieval from 1216 to $1220 \mathrm{~cm}^{-1}$ and 1221 to $1234 \mathrm{~cm}^{-1}$, case (2): joint acetone/aerosol/interfering species retrieved from 1160 to $1260 \mathrm{~cm}^{-1}$, case (3): estimated error for detection methodology in this paper.

\begin{tabular}{llll}
\hline Error source & Case (1) error (\%) & Case (2) error (\%) & Case (3) error (\%) \\
\hline Temperature (1 K, 1 K) & 3.0 & - & 3.0 \\
Pressure $(4 \%, 1 \%)$ & 9.3 & - & 2.3 \\
$\mathrm{H}_{2} \mathrm{O}(50 \%, 20 \%)$ & 24.2 & - & 9.7 \\
$\mathrm{~N}_{2} \mathrm{O}(10 \%, 5 \%)$ & 8.7 & - & 4.4 \\
$\mathrm{CH}_{4}(10 \%, 5 \%)$ & 2.4 & - & 1.2 \\
$\mathrm{CO}_{2}(1 \%, 1 \%)$ & 0.2 & - & 0.2 \\
Spectroscopy (10\%) & 10.0 & 10.0 & 10.0 \\
Total systematic (RSS) & 29.4 & - & 15.1 \\
Random errors (noise) & 3.1 & 2.1 & 3.1 \\
Total accuracy & 29.6 & 10.2 & 15.4 \\
\hline
\end{tabular}

Table 5. Chief error sources for formic acid at $10.4 \mathrm{~km}$ tangent altitude, channel 2, assuming HITRAN 2000 spectroscopy and minimum spectroscopic error. Case (1): joint formic acid/aerosol retrieval from 1104.5 to $1106 \mathrm{~cm}^{-1}$, case (2): joint formic acid/aerosol/interfering species retrieved from 1060 to $1150 \mathrm{~cm}^{-1}$, case (3): estimated error for detection methodology in this paper.

\begin{tabular}{llll}
\hline Error source & Case (1) error (\%) & Case (2) error (\%) & Case (3) error (\%) \\
\hline Temperature (1 K, 1 K) & 32.8 & - & 32.8 \\
Pressure $(4 \%, 1 \%)$ & 26.2 & - & 6.6 \\
$\mathrm{H}_{2} \mathrm{O}(50 \%, 20 \%)$ & 2.2 & - & 0.9 \\
$\mathrm{O}_{3}(10 \%, 5 \%)$ & 1.2 & - & 0.6 \\
$\mathrm{CFC}-12(5 \%, 2 \%)$ & 0.9 & - & 0.4 \\
Spectroscopy (15\%) & 15.0 & 15.0 & 15.0 \\
Total systematic (RSS) & 44.7 & - & 36.7 \\
Random errors (noise) & 2.3 & 0.8 & 2.3 \\
Total accuracy & 44.8 & 15.0 & 36.8 \\
\hline
\end{tabular}

\section{Conclusions}

The MIPAS-B2, which is a high quality, high spectral resolution, infra-red interferometer, has provided an excellent opportunity to look for the spectral signatures of trace organic species in observations of emission from the upper troposphere. The signatures of PAN and acetone have been observed for the first time, using the data from flight 6 , and their presence confirmed by detection of spectral shapes of the target molecular bands and detection of known spectral signatures (CFC-12 and HCFC-22). The chief error sources in retrieval of their concentrations have been estimated. The evidence for the detection of PAN has been further strengthened by the identification of two spectral bands of PAN which are both very well fitted by the same value for the PAN concentration; individual fits to the PAN bands were identical to within 10 pptv which is within the random errors associated with the retrievals. A signature of formic acid has also been determined by the detection methodology of this study, providing the first observation of its signature in thermal emission as opposed to solar occultation, with observation of all three branches of formic acid, i.e. the intense $\mathrm{Q}$ branch and the less strong $\mathrm{P}$ and $\mathrm{R}$ branches. However, the known structure to the $\mathrm{P}$ and $\mathrm{R}$ branches cannot be definitively observed in the fitted spectra.

The detection methodology also provides an inferred concentration for the trace gases. The chief geophysical error sources in the deduced target gas concentrations have been investigated and these are helpful in indicating the likely accuracy of retrievals in the mid-latitudes from thermal emission spectrometers. They also show which atmospheric variables need to be well constrained in order for an optimised retrieval to be obtained. It is shown that retrievals in the $1163 \mathrm{~cm}^{-1}$ band of PAN are likely to have lower systematic errors than in the $794 \mathrm{~cm}^{-1}$ band. Temperature, pressure, water vapour and $\mathrm{CCl}_{4}$ are the most important sources of error. 
Similarly for acetone, water vapour is the most critical parameter. Hence whilst accuracies of $30 \%$ or better can be obtained in mid-latitudes, even when water vapour knowledge is not particularly good (50\% uncertainty), the requirement for higher accuracy water vapour knowledge increases as the water vapour amount increases at lower altitudes and towards the tropics. For formic acid, the $\mathrm{Q}$ branch was investigated since this is the clearest feature present in the spectra observed in this flight. Accuracy was limited particularly by temperature knowledge to just under $40 \%$ for our detection method. Retrievals of formic acid are therefore likely to be particularly demanding. In addition, the values for formic acid were inferred using the HITRAN 2000 spectroscopic database. There is considerable uncertainty in the absolute values of intensity for this band of formic acid and these will also have to be resolved for absolute values for formic acid concentrations to be interpreted. These uncertainties are systematic and so global retrievals of formic acid indicating relative variations will still be invaluable given the inability of atmospheric chemistry models to capture formic acid concentrations and variations.

With detection of the spectral signatures of these organic compounds, it is clear that Fourier transform spectrometers could deliver considerable information on upper tropospheric concentrations of PAN, acetone and formic acid in many regions of the world. Candidate space instruments for further analysis include the MIPAS on ENVISAT (MIPAS-E) and the Atmospheric Chemistry Experiment (ACE) on SCISAT (Bernath et al., 2005); the latter is solar occultation rather than limb emission so it has the same wavelength information but not the latitudinal coverage on a particular day. Our initial results (e.g. Allen, 2005c) indicate that sensing of our target compounds with MIPAS-E is feasible. In a further paper to be submitted, we will characterise the ability of the MIPAS-E satellite instrument to measure PAN in particular. The potential for transforming our knowledge of these compounds from observations should be exploited and should provide a very good basis on which to test global models of the upper troposphere.

Acknowledgements. The authors would like to acknowledge the NERC for support of $\mathrm{G}$. Allen through a $\mathrm{PhD}$ studentship under its COSMAS programme (grant ref: NER/T/S/2000/01087), A. Waterfall and D. Moore (grant ref: NE/D004829/1) through a standard grant.

Edited by: A. Richter

\section{References}

ACECHEM: Definition of mission objectives and observational requirements for an atmospheric chemistry explorer mission. ESA contract: 14048/98/NL/GD, 2001.

Allen, G., Remedios, J. J., Newnham, D. A., Smith, K. M., and Monks, P. S.: Improved mid-infrared cross-sections for perox- yacetyl nitrate (PAN) vapour, Atmos. Chem. Phys., 5, 47-56, 2005a.

Allen, G., Remedios, J. J., and Smith, K. M.: Low temperature midinfrared cross-sections for peroxyacetyl nitrate (PAN) vapour, Atmos. Chem. Phys., 5, 3153-3158, 2005 b.

Allen, G.: The infra-red remote sensing of Peroxyacetyl Nitrate in the upper troposphere, Ph.D. thesis, University of Leicester, http://www.leos.le.ac.uk/publications/pdfs/theses/GA_ thesis_final.pdf, 2005c.

Arnold, S. R., Chipperfield, M. P., Blitz, M. A., Heard, D. E., and Pilling, M. J.: Photodissociation of acetone: Atmospheric implications of temperature-dependent quantum yields, Geophys. Res. Lett., 31(7), doi:10.1029/2003GL019099, L07110, 2004.

Arnold, S. R., Chipperfield, M. P., and Blitz, M. A.: A threedimensional model study of the effect of new temperaturedependent quantum yields for acetone photolysis, J. Geophys. Res., 110, D22305, doi:10.1029/2005JD005998, 2005.

Bernath, P.F., McElroy, C. T., Abrams, M. C., et al.: Atmospheric Chemistry Experiment (ACE): Mission overview, Geophys. Res. Lett. 32, L15S01, doi:10.1029//2005GL022386, 2005.

Blitz, M. A., Heard, D. E., Pilling, M. J., Arnold, S. R., and Chipperfield, M. P.: Pressure and temperature-dependent quantum yields for the photodissociation of acetone between 279 and $327.5 \mathrm{~nm}$, Geophys. Res. Lett., 31, L06111, doi:10.1029/2003GL018793, 2004.

Burrows, J. P., Weber, M., Buchwitz, M., Rozanov, V. V., Ladstätter-Weilenmayer, A., Richter, A., De Beek, R., Hoogen, R., Bramstedt, K., and Eichmann, K. U.: The global ozone monitoring experiment (GOME): Mission concept and first scientific results, J. Atmos. Sci., 56(2), 151-175, 1999.

Chebbi, A. and Carlier, P.: Carboxylic acids in the troposphere: occurrence sources and sinks: A review, Atmos. Environ., 30(24), 4233-4249, 1996.

Dufour, G., Boone, C. D., Rinsland, C. P., and Bernath, P. F.: First space-borne measurements of methanol inside aged southern tropical to mid-latitude biomass burning plumes using the ACE-FTS instrument, Atmos. Chem. Phys., 6, 3463-3470, 2006, http://www.atmos-chem-phys.net/6/3463/2006/.

Dudhia, A., Jay, V. L., and Rodgers, C. D.: Microwindow selection for high-spectral resolution sounders, Appl. Opt., 41, 18, 36653673, 2002.

Edwards, D. P.: genln2: a general line-by-line atmospheric transmittance and radiance model: version 3.0 description and users guide, Rep. NCAR /TN-367 +STR, National Center for Atmospheric Research, Boulder, Colo., 1992.

Emmons L. K., Hauglustaine, D. A., Müller, M. A., Carroll, M. A., Brasseur, G. P., Brunner, D., Staehelin, J., Thouret, V., and Marenco, A.: Data composites of airborne observations of tropospheric ozone and its precursors, J. Geophys. Res., 105, $20497-$ $20538,2000$.

Fischer, H. and Oelhaf, H.: Remote sensing of vertical profiles of atmospheric trace constituents with MIPAS limb-emission spectrometers, Appl. Opt., 35, 2787-2796, 1996.

Folkins, I. and Chatfield, R.: Impact of acetone on ozone production and $\mathrm{OH}$ in the upper troposphere at high NOx, J. Geophys. Res., 105, 11 585-11 589, 2000.

Friedl-Vallon, F., Maucher, G., Trieschmann, O., and Oelhaf, H.: MIPAS-B Flight report: Flight number 6 of 7/8.5.98 from Aire sur l'Adour/France. Revision 1 of 22.12.1999. Technical re- 
port, IMK, Forschungzentrum, Karlsruhe, ESA contract No. 12078/96/NL/GS, 1999.

Friedl-Vallon, F., Maucher, G., Kleinert, A., Lengel, A., Keim, C., Oelhaf, H., Fischer, H., Seefeldner, M., and Trieschmann, O.: Design and characterization of the balloon-borne Michelson Interferometer for Passive Atmospheric Sounding (MIPAS-B2), Appl. Opt., 43, 3335-3355, 2004.

Goldman, A., Murcray, F. H., Murcray, D. G., and Rinsland, C. P.: A search for formic acid in the upper troposphere: A tentative identification of the $1105 \mathrm{~cm}^{-1} \mathrm{n} 6$ band Q branch in highresolution balloon-borne solar absorption spectra, Geophys. Res. Lett., 11, 307-310, 1984.

Hauglustaine D. A., Brasseur, G. P., Walters, S., Rasch, P. J., Müller, J-F., Emmons, L. K., and Carroll, M. A.: Mozart: a global chemical transport model for ozone and related chemical tracers Part 2: model results and evaluation, J. Geophys. Res., 103, 28 29128335, 1998.

Holzinger, R., Williams, J., Salisbury, G., Klüpfel, T., de Reus, M., Traub, M., Crutzen, P. J., and Lelieveld, J.: Oxygenated compounds in aged biomass burning plumes over the Eastern Mediterranean: evidence for strong secondary production of methanol and acetone, Atmos. Chem. Phys., 5, 39-46, 2005, http://www.atmos-chem-phys.net/5/39/2005/.

Horowitz, L., Walters, S., Mauzerall, D. L., Emmons, L. K., Rasch, P., Granier, C., Tie, X., Lamarque, J. F., Schultz, M., Tyndall, G. S., Orlando, J. J., and Brasseur, G. P.: A global simulation of tropospheric ozone and related tracers: Description and evaluation of MOZART version 2, J. Geophys. Res., 108(D24), 4784, doi:10.1029/2002JD002853, 2003.

IPCC: Climate Change 2001: The Scientific Basis.Contribution of Working Group I to the Third Assessment Report of the Intergovernmental Panel on Climate Change (IPCC), edited by: Houghton, J. T., Ding, Y., Griggs, D. J., Noguer, M., van der Linden, P. J., and Xiaosu, D., Cambridge University Press, UK, pp 944, 2001.

Jacob, D. J.: The oxidizing power of the atmosphere. Chapter for the Handbook of Weather, Climate and Water, edited by: Potter, T., Colman, B., and Fishman, J., Mc-Graw Hill, 2000.

Jacob, D. J., Field, B. D., Jin, E., Bey, I., Li, Q., Logan, J. A., and Yantosca, R. M.: Atmospheric budget of acetone, J. Geophys. Res., 107(D10), 4100, doi:10.1029/2001JD000694, 2002.

Jay, V.: Remote sounding of the atmosphere by high-resolution spectroscopy, DPhil thesis, Oxford University, 2000.

Lelieveld, T., Berresheim, H., and Borrmann, S.: Global air pollution crossroads over the Mediterranean, Science, 298(5594), 794-799, 2002.

McKeen, S. A., Gierczak, T., Burkholder, J. B., Wennberg, P. O., Hanisco, T. F., Keim, E. R., Gao, R.-S., Liu, S. C., Ravishankara, A. R., and Fahey, D. W.: The photochemistry of acetone in the upper troposphere: A source of odd-hydrogen radicals, Geophys. Res. Lett., 24(24), 3177-3180, 1997.

Miyazaki, Y., Kondo, Y., Koike, M., Fuelberg, H. E., Kiley, C. M., Kita, K., Takegawa, N., Sachse, G. W., Flocke, F., Weinheimer, A. J., Singh, H. B., Eisele, F. L., Zondlo, M., Talbot, R. W., Sandholm, S. T., Avery, M. A., and Blake, D. R.: Synoptic-scale transport of reactive nitrogen over the western Pacific in spring, J. Geophys. Res., 108(D20), 8788, doi:10.1029/2002JD003248, 2003.

Montzka, S. A., Butler, J. H., Elkins, J. W., Thompson, T. M.,
Clarke, A. D., and Lock, L. T.: Present and future trends in the atmospheric burden of ozone-depleting halogens, Nature, 398, 690-694, 1999.

Norton, R. H. and Beer, R.: New apodising functions for Fourier spectrometry, J. Opt. Soc. A., 66, 259, 1976.

Norton, R. H. and Beer, R.: New apodising functions for Fourier spectrometry - Erratum, J. Opt. Soc. A., 67, 419, 1977.

Perrin, A., Rinsland, C. P., and Goldman, A.: Spectral parameters for the $n u_{6}$ region of $\mathrm{HCOOH}$ and its measurement in the infrared tropospheric spectrum, J. Geophys. Res., 104, $18661-$ $18666,1999$.

Pöschl, U., Williams, J., Hoor, P., Fischer, H., Crutzen, P. J., Warneke, C., Holzinger, R., Hansel, A., Jordan, A., Lindinger, W., Scheeren, H. A., Peters, W., and Lelieveld, J.: High acetone concentrations throughout the $0-12 \mathrm{~km}$ altitude range over the tropical rainforest in Surinam, J. Atmos. Chem., 38(2), 115-132, 2001.

Reiner, T., Möhler, O., and Arnold, F.: Measurements of acetone, acetic acid and formic acid in the northern midlatitude upper troposphere and lower stratosphere, J. Geophys. Res., 104(D11), 13 943-13 952, 1999.

Remedios, J. J.: Extreme atmospheric constituent profiles for MIPAS, Proceedings of the European Symposium on atmospheric measurements from space, Vol. 2, ESTEC, Nordwijk, Netherlands, 20-22 January, 779-783, 1999.

Rinsland, C.P., Mahieu, E., Zander, R., Goldman, A., Wood, S., and Chiou, L.: Free tropospheric measurements of formic acid $(\mathrm{HCOOH})$ from infrared ground-based solar absorption spectra: Retrieval approach, evidence for a seasonal cycle and comparison with model calculations, J. Geophys. Res., 109, D18308, doi:10.1029/2004JD004917, 2004.

Roberts, J. M., Flocke, F., Chen, G., Gouw, J., Holloway, J. S., Hubler, G., Neuman, J. A., Nicks, D. K., Nowak, J. B., Parrish, D. D., Ryerson, T. B., Sueper, D. T., Warneke, C., and Fehsenfeld, F. C.: Measurement of peroxycarboxylic nitric anhydrides (PANs) during the ITCT 2K2 aircraft intensive experiment, J. Geophys. Res., 109, D23S21, doi:10.1029/2004JD004960, 2004.

Rodgers, C. D.: Inverse methods for atmospheric sounding: Theory and practice, World Scientific Publishing, Singapore, 2000.

Rothman, L. S., Barbe, A., Benner, D.C., Brown, L. R., CamyPeyret, C., Carleer, M. R., K. Chance, K, Clerbaux, C., Dana, V., Devi, V. M., Fayth, A. Flaud, J.M., Gamache, R. R., Goldman, A., Jacquemart, D., Jucks, K. W., Lafferty, W. J., Mandin, J.-Y., Massie, S. T., Nemtchinov, V., Newnham, D. A., Perrin, A., Rinsland, C. P., Schroeder, J., Smith, K. M., Smith, M. A. H., Tang, K., Toth, R. A., Vander Auwera, J., Varanasi, P., and Yoshino, K.: The HITRAN molecular spectroscopic database: edition of 2000 including updates through 2001, J. Quant. Spectrosc. Radiat. Trans., 82(1-4), 5-44, 2003.

Russo, R. S., Talbot, R. W., Dibb, J. E., Scheuer, E., Seid, G., Jordan, C. E., Fuelberg, H. E., Sachse, G. W., Avery, M. A., Vay, S. A., Blake, D. R., Blake, N. J., Atlas, E., Fried, A., Sandholm, S. T., Tan, D., Singh, H. B., Snow, J., and Heikes, B. G.: Chemical composition of Asian continental outflow over the western Pacific: Results from Transport and Chemical Evolution over the Pacific (TRACE-P), J. Geophys. Res., 108(D20), 8804, doi:10.1029/2002JD003184, 2003.

Shephard, M. W., Goldman, A., Clough, S. A., and Mlawer, E. W.: 
Spectroscopic improvements providing evidence of formic acid in AERI-LBLRTM validation spectra, J. Quant. Spectrosc. Radiat. Trans., 82(1-4), 207-218, 2003.

Sihra, K., Hurley, M. D., Shine, K. P., and Wallington, T. J.: Updated radiative forcing estimates of 65 halocarbons and nonmethane hydrocarbons. J. Geophys. Res., 106(D17), $20493-$ $20505,2001$.

Singh, H. B. and Hanst, P. L.: Peroxyacetyl nitrate (PAN) in the unpolluted atmosphere: An important reservoir for nitrogen oxides, Geophys. Res. Lett., 8, 941-944, 1981.

Singh, H., Chen, Y., Tabazadeh, A., Fukui, Y., Bey, I., Yantosca, R., Jacob, D., Arnold, F., Wohlfrom, K., Atlas, D., Flocke, F., Blake, D., Blake, N., Heikes, B., Snow, J., Talbot, R., Gregory, G., Sachse, G., Vay, S., Kondo, Y., et al.: Distribution and fate of selected oxygenated organic species in the troposphere and lower stratosphere over the Atlantic, J. Geophys. Res., 105, 3795-805. 2000.

Stowasser, M., Oelhaf, H., Wetzel, G., Friedl-Vallon, F., Maucher, G., Seefeldner, M., Trieschmann, O., von Clarmann, T., and Fischer, H.: Simultaneous measurements of $\mathrm{HDO}, \mathrm{H}_{2} \mathrm{O}$ and $\mathrm{CH}_{4}$ with MIPAS-B: Hydrogen budget and indication of dehydration inside the polar vortex, J. Geophys. Res., 104, 19213-19255, 1999.

Talukdar, R. K., Burkholder, J. B., Schmoltner, A., Roberts, J. M., Wilson, R. R., and Ravishankara, A. R.: Investigation of loss processes for peroxyacetyl nitrate in the atmosphere: UV photolysis and reaction with OH, J. Geophys. Res., 100, 14 163-14 173, 1995.

Toon, G. C., Farmer, C. B., and Norton, R. H.: Detection of stratospheric $\mathrm{N}_{2} \mathrm{O}_{5}$ by infrared remote sounding, Nature, 319, 570$571,1986$.
Trieschmann, O.: Level 0 to $1 \mathrm{~b}$ Data Processing of the MIPASB2 balloon-borne Fourier Transform Spectrometer, revision 1.0 of 10.04.2000. Technical report, IMK, Forschungszentrum, Karlsruhe, ESA contract No. 112078/96/NL/GS, 2000.

Vander Auwera, J.: Proceedings of the NATO Advanced Research Workshop on Remote Sensing of the Atmosphere for Environmental Security, Rabat, Morocco, 16-19 November 2005, NATO Security through Science Series, edited by: Perrin, A., Ben SariZizi, N., and Demaison, J., Springer, 123-137, 2006.

von Kuhlmann, R, Lawrence, M. G., and Crutzen, P. J.: A model for studies of tropospheric ozone and nonmethane hydrocarbons: Model evaluation of ozone-related species, J. Geophys. Res., 108, 4729, doi:10.1029/2002JD003348, 2003.

Wang, Y., Jacob, D. J., and Logan, J. A.: Global simulation of tropospheric O3-NOx-hydrocarbon chemistry. 3 Origin of tropospheric ozone and effects of NMHC, J. Geophys. Res., 103, 10757-10 767, 1998.

Waterfall, A.: Measurement of Organic Compounds in the Upper Troposphere using Infrared Remote Sensing, D. Phil. Thesis, University of Oxford, http://www.leos.le.ac.uk/publications/ pdfs/theses/thesis_A_Waterfall_Remote_Sensing_Organics_UT. pdf, 2003.

Wittrock, F., Richter, A., Oetjen, H., Burrows, J. P., Kanakidou, M., Myriokefalitakis, S., Volkamer, R., Beirle, S., Platt, U., and Wagner, T.: Simultaneous global observations of glyoaxl and formaldehyde from space, Geophys. Res. Lett., 33, L16804, doi:10.1029/2006GL026310, 2006. 